\title{
Financial Statement Fiscal Years 2009-2010 and Previous Fiscal Year
}

\begin{tabular}{|c|c|c|c|}
\hline & $2009 / 2010$ & $2008 / 2009$ & Change \\
\hline Opening balance & $\$ 31,761.90$ & $\$ 4,026.39$ & $\$ 27,735.51$ \\
\hline \multicolumn{4}{|l|}{ Revenue and income } \\
\hline \multicolumn{4}{|l|}{ Revenue } \\
\hline Membership dues & $\$ 32,190.00$ & $\$ 41,780.00$ & $-\$ 9,590.00$ \\
\hline Library subscriptions & $\$ 2,355.00$ & $\$ 75.00$ & $\$ 2,280.00$ \\
\hline Conference registrations & $\$ 51,115.00$ & $\$ 44,600.00$ & $\$ 6,515.00$ \\
\hline Paper submission fees & $\$ 13,320.00$ & $\$ 13,820.00$ & $-\$ 500.00$ \\
\hline Conference booths and ads & $\$ 6,850.00$ & $\$ 2,700.00$ & $\$ 4,150.00$ \\
\hline Sales of luncheon tickets & $\$ 2,200.00$ & $\$ 5,120.00$ & $-\$ 2,920.00$ \\
\hline Other (royalties, miscellaneous) & $\$ 15,022.09$ & $\$ 12,247.37$ & $\$ 2,774.72$ \\
\hline Total revenue & $\$ 123,052.09$ & $\$ 120,342.37$ & $\$ 2,709.72$ \\
\hline \multicolumn{4}{|l|}{ Income } \\
\hline Interest chase savings & $\$ 1.10$ & $\$ 1.25$ & $-\$ 0.15$ \\
\hline Total income & $\$ 1.10$ & $\$ 1.25$ & $-\$ 0.15$ \\
\hline Total revenue and income & $\$ 123,053.19$ & $\$ 120,343.62$ & $\$ 2,709.57$ \\
\hline \multicolumn{4}{|l|}{ Expenses } \\
\hline Eastern Economic Journal & $\$ 43,489.00$ & $\$ 3,593.50$ & $\$ 39,895.50$ \\
\hline Headquarters & $\$ 21,000.00$ & $\$ 20,000.00$ & $\$ 1,000.00$ \\
\hline Eckstein/koford prize & $\$ 1,000.00$ & $\$ 220.43$ & $\$ 779.57$ \\
\hline Credit card fees & $\$ 4,815.34$ & $\$ 4,048.58$ & $\$ 766.76$ \\
\hline Legal fees & $\$ 0.00$ & $\$ 0.00$ & $\$ 0.00$ \\
\hline CPA fees & $\$ 1,800.00$ & $\$ 1,750.00$ & $\$ 50.00$ \\
\hline Bank fees & $\$ 58.00$ & $\$ 26.00$ & $\$ 32.00$ \\
\hline Insurance $\mathrm{D} \& \mathrm{O}$ & $\$ 1,050.00$ & $\$ 1,050.00$ & $\$ 0.00$ \\
\hline Insurance liability & $\$ 829.03$ & $\$ 814.03$ & $\$ 15.00$ \\
\hline Hotel deposits & $\$ 0.00$ & $\$ 0.00$ & $\$ 0.00$ \\
\hline Conference expense & $\$ 68,634.41$ & $\$ 66,051.06$ & $\$ 2,583.35$ \\
\hline Summer payment to exec director & $\$ 4,500.00$ & $\$ 9,150.00$ & $-\$ 4,650.00$ \\
\hline Fed challenge & $\$ 4,000.00$ & $\$ 0.00$ & $\$ 4,000.00$ \\
\hline Miscellaneous (bank fees, refunds) & $\$ 1,211.67$ & $\$ 575.21$ & $\$ 636.46$ \\
\hline Total expenses & $\$ 152,387.45$ & $\$ 107,278.81$ & $\$ 45,108.64$ \\
\hline Revenue + Income-Expenses & $-\$ 29,334.26$ & $\$ 13,064.81$ & $-\$ 42,399.07$ \\
\hline $\mathrm{CD}$ into checking & $\$ 0.00$ & $\$ 12,706.05$ & \\
\hline Vanguard into checking & $\$ 5,000.00$ & $\$ 0.00$ & \\
\hline Closing balance & $\$ 7,427.64$ & $\$ 29,797.25$ & \\
\hline \multicolumn{4}{|l|}{ Other assets } \\
\hline \multicolumn{4}{|l|}{$C D$} \\
\hline Value & $\$ 0.00$ & $\$ 0.00$ & $\$ 0.00$ \\
\hline \multicolumn{4}{|l|}{ Vanguard } \\
\hline Acct value & $\$ 77,395.88$ & $\$ 71,480.60$ & $\$ 5,915.28$ \\
\hline Total assets & $\$ 84,823.52$ & $\$ 101,277.85$ & $-\$ 16,454.33$ \\
\hline
\end{tabular}

